\title{
SOBRE UNA NUEVA TRADUCCIÓN AL ESPAÑOL DE IL LIBRO DEL CORTEGIANO
}

\begin{abstract}
Resumen. Las tradiciones culturales europeas han llevado a cabo traducciones diversas de las obras literarias más excelentes de su entorno cultural. El canon filológico hispánico ha negado esta posibilidad a la obra de Castiglione, Il Cortegiano (1528), desde que se publicara la famosa traducción de Boscán en Barcelona, en 1534. Aquí se argumenta la necesidad de revocar una postura.
\end{abstract}

Palabras clave: Renacimiento, Castiglione, Boscán, traducción.

\section{Introducción}

Han pasado más de 480 años desde la publicación de la traducción de Il libro del cortegiano, de Baldassare Castiglione, llevada a cabo por el español Juan Boscán (fines del siglo XIV-1540). No existe publicada una nueva traducción de semejante libro. Las ediciones modernas que conocemos, como la de Pozzi (1994 [2011]), por ejemplo, son deudoras, en gran medida, de otras ediciones como la de Fabié (1873), González Palencia (1943) o Menéndez y Pelayo (1942), ediciones que, en lo esencial, reproducen el texto original de 1534. Lo mismo sucede con la edición más moderna de Alianza Editorial (2001), con prólogo de Ángel Crespo. En el transcurso de estos cinco siglos, el canon cultural imperante no haya encontrado motivo alguno para manifestar lo evidente, a saber, que un lector hispánico no especialista en la lengua española del renacimiento, en particular del español preclásico (1474-1525), no va a encontrar fácil, de ninguna manera, la lectura de una sola página de la maravillosa traducción de Juan Boscán publicada en 1534. Sin embargo, eso es lo que parece derivarse de los hechos. ¿Es tan importante el peso de la tradición

\footnotetext{
* Universidad de Valladolid.
} 
cultural que ha podido obligar a un silencio traductor de cinco siglos? Autores clásicos de la cultura española renacentista, como el mismo inductor de la traducción, Garcilaso de la Vega y sus palabras laudatorias sobre la "naturalidad" de la traducción de Boscán la han incorporado al mundo cultural de lo inamovible. Para subrayar dicha sentencia, se han de añadir estudios en el siglo XX de Menéndez y Pelayo en 1942 y 1945 y los numerosos de la italianista e hispanista Margherita Morreale (1955, 1958, 1959). Todos ellos parten de hecho de la alta calidad de la traducción de Juan Boscán, de su trabajo admirable en cuanto a la versión española. A la tarea encomiable de Boscán, cabe añadir la postura elogiosa de los estudiosos del siglo XX. Para Menéndez y Pelayo (1945: 15-16, 18), por ejemplo, Boscán es «el [...] reformador de la métrica castellana» y «el patriarca de la escuela ítalo-hispana». Que sepamos, los editores modernos de la obra, como Pozzi (1994/2011) y Crespo (2001) reproducen la traducción de Boscán de 1534 con ninguna o algunas correcciones de erratas que pasaron inadvertidas a lo largo de los siglos.

Traducir al español de hoy una obra escrita hace casi cinco siglos, a pesar de pertenecer a una cultura tan cercana como la italiana, ha de ser ciertamente más complicado que hacerlo con una obra contemporánea de esa misma lengua: el texto original puede producir extrañezas e incluso incomprensiones en el lector actual y es previsible que los modos lingüísticos al uso en los comienzos del siglo XVI ya no estén igualmente vigentes en el siglo XXI. Si hablamos de traducción de dicho texto empleando la distinción de Roman Jacobson ([1956] 1992: 145) de, pongamos por caso, Il libro del Cortegiano, resulta que, al día de hoy, no solo sería precisa una traducción interlingüística (del italiano al español) sino también una traducción intralingüística (del español del siglo XVI al español del siglo XXI). Sin embargo, Menéndez y Pelayo (1945: 181-182, nota 1) indica lo siguiente al comparar la obra de Boscán respecto a Il Cortigiano con la que Juan Nicasio Gallego lleva a cabo con la obra de Manzini I promessi sposi:

¡Cuánto se distinguen los traductores fieles y elegantes de los serviles y adocenados; [...] y el que quiera convencerse de la primacía que continúa disfrutando Boscán sobre todos los traductores de prosa italiana en cualquier tiempo, primacía tan indisputable como la que goza Jáuregui entre los traductores poéticos por su Aminta, no tiene más que cotejar El Cortesano con la que pasa por la más esmerada de las labores de este género en el siglo XIX, por la novela de Manzoni, cuyo intérprete fue nada menos que D. Juan Nicasio Gallego; y comprenderá lo que va del uno al otro y lo mucho que hemos retrocedido en materia de estilo y lengua.

Se producen ciertas anomalías que desvirtúan la opinión del crítico. En primer lugar, la comparación debería producirse entre traducciones 
diversas de la misma obra para poder cotejar su calidad intrínseca. Pero aquí lo que hay es una comparación supuesta entre las traducciones de dos obras distintas, de distintos autores (Castiglione y Manzoni), pertenecientes a épocas diversas de la historia del italiano (renacentista y moderna decimonónica) y autores de dos tipos de prosa muy distante (coloquio ciceroniano neoplatónico frente a novela moderna). En segundo lugar, la crítica implica (porque nunca se explicita), que la alta calidad de la traducción de Boscán impide que una traducción moderna al español del siglo $\mathrm{XX}$ sea, simplemente, algo así como una temeridad condenada de antemano al fracaso. Ante esta avalancha de alabanzas el mundo cultural hispánico no podía quedar sino anonadado. El canon está tan fundamentado por la autoridad literaria y crítica que impide todo remozamiento de la obra traducida. Carecía de sentido hacerse cargo de una nueva y, a todas luces, condenada al fracaso de antemano, traducción de Il cortegiano.

Cabe preguntarse si esta situación es extensible a otras culturas de nuestro entorno. En el caso del inglés, por ejemplo, hubo una primera traducción del libro cuarto de Il Libro del Cortegiano a cargo de Thomas Hoby en 1561, The Book of the Courtier, que fue reeditada también en 1900 en Londres por Walter Raleig y David Nutt. Sin embargo, ya en pleno siglo $X X$, tenemos otra traducción, la de Charles S. Singleton, publicada por vez primera en Doubleday en 1959 y reeditada en Norton Critical Edition en 2002. La de Singleton es considerada la mejor de entre las traducciones llevada a cabo al inglés, aunque no sea la única. El interés por Il Cortegiano es de largo alcance en la cultura anglosajona, como demuestra desde bien temprano la monografía de J. Cartwright (1908), B. Castiglione, the Perfect Courtier, his Life and Letters: 1478-1529. Dicho interés que despierta en el ámbito anglosajón se vio refrendado con la publicación en 1995 de la obra de Peter Burke The Fortunes of the Courtier. The European Reception of Castiglione's Cortegiano.

Del francés, se han elaborado nada menos que tres traducciones desde la primera impresión de Il Cortegiano. La primera de ellas se atribuye a Jacques Colin d'Auxerre (1537), tan solo nueve años después de la publicación del original. En 1585 Gabriel Chappuys publica en Lyon la segunda traducción al francés con el texto italiano confrontado. El abad Jean-Baptiste Duhamel publica la tercera traducción al francés en 1690, abreviada y edulcorada como resultado de la censura impuesta por la Iglesia católica. Hay otras traducciones más desde el siglo XVII: Alain Pons publicó una traducción modernizada del texto de Gabriel Chappuys en la editorial Gérad Leborici en el siglo XX. Se han publicado ya cuatro traducciones de Il cortegiano, al francés desde 1537 (Chavy, 1981: 
287 y ss.). Para el español, la situación es extraordinaria. Desgranamos aquí algunos de los argumentos favorables a las traducciones modernas de Il Cortegiano.

1. Obras de gran impacto sobre la teoría política de comienzos del siglo XV, como Il Principe (1513), de Niccolò Macchiavelli, escritas en el italiano de comienzos del siglo XVI, conoce, al menos, tres manuscritos españoles entre los siglos XVII y XVIII y dos ediciones modernas en el español del siglo XIX (Alberto Lista en 1821, en Madrid y la de otro traductor de nombre desconocido en 1842, en Barcelona), según ha investigado Arbulu Barturen (2013: 25). En el siglo XX y en el XXI hay varios traductores que se encargan de darnos sus versiones. Un lector hispánico de hoy puede leer la obra de Macchiavelli por haber sido traducida de una manera admirable al español peninsular, como es el caso de la versión del Eli Leonetti Jungl en Austral, del año 2012, la de Emilio Blanco en 2013 en la editorial Ariel Quintaesencia o la de Miguel Ángel Granada Martínez de Alfaguara en 2010. La más reciente es de otra traductora española, Pilar González Rodríguez, en la editorial Navona (2018). La situación se repite respecto a Il Principe, según indica Alcira Beatriz Bonilla (2016: 265) en la Argentina, con una traducción publicada a cargo de Antonio Tursi (2002) y otra al cuidado de Ivana Costa y Horacio González (2012). Por tanto, solo para el siglo XXI hemos contado, al menos, las traducciones de seis profesionales en dos países hispánicos diferentes. La obra de Castiglione que aquí tratamos es un complemento natural a la teoría política de Il Principe: se trata de un magnífico tratado dialógico de retórica cortesana (Plett, 1999: 442-443; Larusso, 1999: 65) en lengua vulgar, opuesta a la retórica humanista, por lo común escrita en latín. Lo mismo sucede también con el Orlando furioso, de Ludovico Ariosto (1516), que fue traducida por Juan de Urrea en 1549 y que no ha conocido otras traducciones hasta el siglo XIX (la del conde de Cheste de 1853) y el siglo XX (Isabel Andrés Lucas, 2002; Cesare Segre y María de las Nieves Muñiz, 2002 y, por último, para el siglo XXI, la de José María Micó de 2005). La traducción de Micó le supuso a su autor el Premio Nacional de Traducción en 2005.

2. Lo decisivo en cada obra, desde la perspectiva traductora, es la eficacia comunicativa y más si han transcurrido varios siglos desde su redacción original y el periodo histórico en el que puede acercarse a ella con dificultades de comprensión un lector contemporáneo (Nord, 2002: 122-123). En segundo lugar, lo más relevante para un traductor de toda época es la idea del receptor potencial. Para una traducción actual, hay que considerar a un receptor de hoy. Téngase en consideración que respecto a la lengua griega clásica, en la cultura anglosajona han aparecido una 
veintena de traducciones de la Odisea, solo en los últimos 20 años, según Óscar Martínez (2018: 7). A pesar de la cercanía estructural y cultural entre español e italiano, es evidente que cada generación debería contar con su traducción de los clásicos. Sin duda, Il Cortegiano es una obra clásica de nuestra cultura europea compartida, que no ha tenido la misma suerte hasta hoy. Si consideramos, por ejemplo, que una generación aparece cada 40 años, nos hemos perdido, desde 1537, tal vez unas 12 traducciones diversas de Il Cortegiano. Piénsese, por un momento, que El Quijote solo hubiera recibido una traducción al francés o al inglés en el siglo XVII. Ello hubiera supuesto un alejamiento comunicativo evidente entre la obra de Cervantes y los lectores actuales del francés y del inglés. Una situación bien paralela a esta, afortunadamente hipotética, se produce entre los lectores hispánicos actuales de Il Cortegiano.

3. Los lectores modernos del español no tienen por qué interesarse por un texto en su lengua materna que les plantee dificultades derivadas de la distancia lingüística y cultural entre dos puntos históricos separados por casi cinco siglos. Las sucesivas ediciones de la traducción de Il Cortegiano publicadas en nuestro país desde 1534 fueron numerosas durante los siglos XVI y XVII (un total de 13), pero escasas a partir de dichos siglos. Las ediciones posteriores solo han podido interesar a los expertos en literatura española y a los lingüistas de la historia del español especializados en dicha época, la del español renacentista preclásico y clásico. Una traducción actual podría eliminar dicha distancia formal y gran parte de la distancia cultural asociada a ella con una versión adecuada al español culto de hoy. Muchos de los problemas formales resueltos por Boscán de modo admirable para su época (y quizás para una época un tanto anterior desde la perspectiva de la elección léxica y la sintaxis), no deberían resultar problemáticos a un lector culto medio de hoy si tenemos en cuenta la evolución de las lenguas italiana y española, la riqueza léxica y sintáctica de ambas lenguas y los medios técnicos al alcance de los traductores en pleno siglo XXI. Las soluciones hoy preferentes, con todo, habrían de ser, en muchas ocasiones, bastante distintas de las ensayadas por Boscán.

4. Indica Morreale (1959: 56) que la mayoría de los términos cultos empleados por Castiglione (1528) en su texto italiano no se corresponden por los seleccionados por Boscán (1534) en su traducción española. Afirma que «la traducción del Cortesano es para la centuria decimosexta lo que los romanceamientos alfonsíes para el siglo XIII: forja una prosa que ya no quiere ser latina, sino fluir por sus propios cauces en estrecha relación con la lengua hablada» (Morreale, 1959: 279). Sin embargo, se puede comprobar que, hoy en día, la mayor parte de dichos términos "castizos" o "patrimoniales" ya tienen su correlato culto (y funcionalmente 
apropiado), en el léxico del español general del siglo XXI. No existe razón para no incorporarlos al español de hoy. De hecho, muchos de tales cultismos de Castiglione ya habían sido recogidos por Alonso de Palencia desde 1490 en su Universal Vocabulario, lo cual indica que no eran desconocidos en español casi medio siglo antes de que Boscán los rehuyera en su traducción.

5. Afirma también Morreale (1959: 134) que el español del primer tercio del XVI ya dispone de los recursos sintácticos necesarios para dar buena cuenta de los retos de la prosa latinizante de Castiglione. Sin embargo, no se ocupa Morreale de observar que los recursos sintácticos que utiliza Boscán no se corresponden con los que hoy serían propios del castellano culto, sino con los que serían previsibles en la transición entre el español bajomedieval y el renacentista. La mayor parte de los problemas que hoy plantea la traducción de Boscán tienen que ver, propiamente, con la sintaxis antes que con el léxico, precisamente a causa de esa confluencia léxica latinizante que el español ha aceptado ya sin miramientos en época de Juan Boscán.

6. Por último, hay que mencionar un argumento propiamente renacentista para abordar otras traducciones de la obra de Castiglione. Se trata de lo defendido por el propio Castiglione cuando afirma lo siguiente, nada menos, que sobre la obra de Cicerón y sobre la de Virgilio:

E Cicerone in molti lochi riprende molti suoi antecessori; e per biasimare Sergio Galbaafferma che le orazione sue aveano dell'antico; e dice che Ennio ancor sprezzò in alcune cose i suoi antecessori, di modo che, se noi vorremo imitar gli antichi, no gli imiteremo. E Virgilio, che voi dite che imitò Omero, non lo imitò nella lingua (Libro Primo, XXXII, 72).

Dicha argumentación implica que el escritor ha de ser libre para tomar lo conveniente de los autores antiguos y clásicos, sin que esté obligado a aceptar todas sus soluciones formales. Lo dicho respecto a Cicerón y a Virgilio vale, igualmente, para los máximos modelos toscanos, como Petrarca y Boccaccio y así se indica en el siguiente fragmento de Castiglione: «...E veramente gran miseria saria metter fine e non pasar piú avanti di quello che si abbia fatto quasi il primo che ha scritto...» (Il Cortegiano: Libro Primo, XXXVII, 83). La imitación es pertinente para Castiglione, pero a la manera propia del uso actual de la lengua. Se objetará que lo que hace Boscán es traducir, no escribir, pero se quiera o no, nadie duda al día de hoy de que el traductor es un tipo pautado de autor. 


\section{Conclusiones}

El propio Libro del Cortegiano, no es más que una reelaboración y traducción de muchas obras clásicas, a la que hay que añadir una cosmovisión propiamente renacentista. Resulta necesario pensar en términos de traducción tanto interlingüística como intralingüística. Pozzi (2015: 10), tal vez el mayor experto moderno en la obra de Boscán, advierte que al día de hoy, es probable que no empleáramos sus métodos, lo cual implica que una nueva traducción de Il Cortegiano no solo no es un disparate, sino una necesidad cultural en el ámbito hispánico. En la prosa de Diego de San Pedro en su Cárcel de amor ([1493] 2018), por ejemplo, se observa una mayor modernidad léxica y gramatical que la que se halla en el mismo castellano de Boscán escrito cuarenta y dos años después. En definitiva, ya no hay excusas, ni siquiera estéticas, para no intentar traducir de nuevo Il Cortegiano al español contemporáneo, a no ser que consideremos, a la manera de la tradición filológica hispánica, que los receptores actuales de tal obra han de ser los mismos que dejaron de existir hace cosa de cinco siglos.

\section{Bibliografía}

ARBULU BARTUREN, M. B. (2013). «La fortuna de Maquiavelo en España: las primeras traducciones manuscritas y editadas de Il principe», Ingenium, 7, $3-28$.

BONILLA ALCIRA, B. (2016). «Reseña de Maquiavelo, Nicolás, El príncipe (2012) Traducción, introducción, notas y apéndice de Ivana Costa. Posfacio y comentarios de Horacio González, Buenos Aires, Colihue, 416 pp.», Avatares Filosóficos, 3, 265-268.

BURKE, P. (1995). The Fortunes of the Courtier. The European Reception of Castiglio$n e$ 's Cortegiano. Pennsylvania: Penn State University Press.

CASTIGLIONE, B. ([1528] 2014). Il libro del Cortegiano, edizione a cura di Walter Barberis. Torino: Einaudi Classici.

CASTIGLIONE, B. ([1534] 2011/2004). El cortesano, edición de Mario Pozzi. Madrid: Cátedra (trad. J. BOSCÁN).

CRESPO, A. (2001). «Prólogo», en El cortesano. Madrid: Alianza editorial (trad. J. BOSCÁN).

CHAVY, P. (1981). «Les traductions humanistes au début de la Renaissence française: traductions medievales, traductions modernes», Canadian Review of Comparative Literature. Special Issue: Translation in the Renaissence, VIII, 2, 284-306. 
JAKOBSON, R. ([1956] 1992). «On Linguistic Aspects of Translation», en J. BIGUENET \& R. SCHULTE (eds.), Theories of Translation: An Anthology of Essays from Dryden to Derrida. Chicago: University of Chicago Press, 144-151. LARUSSO, D. A. (1999). «La retórica en el Renacimiento italiano», en J. J. MURPHY (ed.), La elocuencia en el Renacimiento. Madrid: Visor, 53-73.

MARTÍNEZ, Ó. (2018). «En busca de Homero», El País, 21.01.2018, IDEAS, 7.

MENÉNDEZ Y PELAYO, M. (1945). Antología de poetas líricos castellanos. Boscán, $X$. Madrid: Consejo superior de Investigaciones Científicas.

MORREALE, M. (1955). «'Cortigiano faceto' y 'Burlas cortesanas': expresiones italianas y españolas para el análisis y descripción de la risa», Boletín de la Real Academia Española, 35, cuaderno 144, 57-84.

MORREALE, M. (1958). «Castiglione y ‘El Héroe', Gracián y ‘Despejo'», Homenaje a Gracián, 137-143 (texto completo en DIALNET).

MORREALE, M. (1959). Castiglione y Boscán: el ideal cortesano en el Renacimiento español, t. I: Estudio léxico-semántico), t. II: Anejos del "Boletín de la Real Academia Española". Madrid: RAE.

NORD, C. (2002). «La traducción como actividad intencional. Conceptos-críticas -malentendidos», en E. SÁNCHEZ TRIGO y Ó. DÍAZ FOUCES (eds.), Traducción E Comunicación, 3, 109-124.

PLETT, H. F. (1999). «Lugar y función del estilo en la poética renacentista», en J. J. MURPHY (ed.), La elocuencia en el Renacimiento. Estudios sobre la teoría y la práctica de la retórica renacentista. Madrid: Visor Libros, 421-443.

POZZI, M. ([1994] 2011). «Introducción», en El cortesano. Madrid: Cátedra, Letras Universales, 9-98 (trad. J. BOSCÁN).

POZZI, M. (2015). «La traduzione del Cortegiano e l'aspirazione spagnola a una cultura digna della nuova condizione imperiale», Laboratoire italien, 16, 1-16 [en línea] <https://journals.openedition.org/laboratoireitalien/932\#tocto1n4>, fecha de consulta: 20 de abril de 2018.

SAN PEDRO DE, D. ([1493] 2018). Cárcel de amor. Arnalte y Lucenda. Sermón, edición de José Francisco Ruiz Casanova. Madrid: Cátedra.

TERRACINI, L. ([1965] 1979). «Valdés: cuidado. Boscán: descuido», Società filologica romana (ed.), Studi di Letteratura Spagnola, Roma: Universita di Roma, 187-209. También en L. TERRACINI (ed.), Lingua come problema nella letteratura spagnola del Cinquecento. Torino: Stampatori. 